A fungal biofilm reactor based on metal structured packing improves the quality of a Gla::GFP fusion protein produced by Aspergillus oryzae

Q. Zune, A. Delepierre, S. Gofflot, J. Bauwens, J. C. Twizere, P. J. Punt, F. Francis, D. Toye, T. Bawin \& F. Delvigne

\section{Applied Microbiology and} Biotechnology

ISSN 0175-7598

Appl Microbiol Biotechnol DOI 10.1007/s00253-015-6608-z
Applied ONLINS

and Microbuwuy y
Biotechnology

Volume 99 Number 10 May 2015

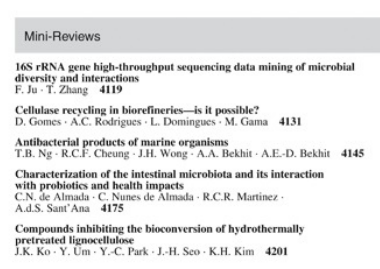

Biotechnological products and process engineering
Tarasted production of secondary metabolites by coexpression

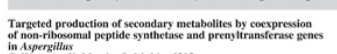

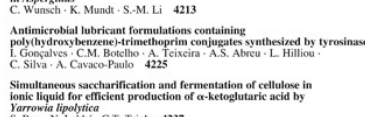

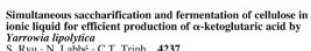

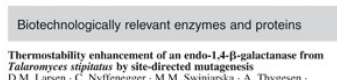

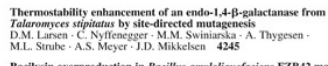

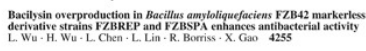

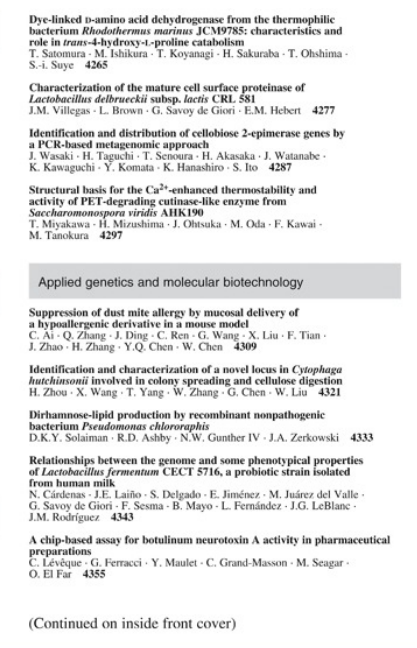

答 Springer

黛 Springer 
Your article is protected by copyright and all rights are held exclusively by SpringerVerlag Berlin Heidelberg. This e-offprint is for personal use only and shall not be selfarchived in electronic repositories. If you wish to self-archive your article, please use the accepted manuscript version for posting on your own website. You may further deposit the accepted manuscript version in any repository, provided it is only made publicly available 12 months after official publication or later and provided acknowledgement is given to the original source of publication and a link is inserted to the published article on Springer's website. The link must be accompanied by the following text: "The final publication is available at link.springer.com". 


\title{
A fungal biofilm reactor based on metal structured packing improves the quality of a Gla::GFP fusion protein produced by Aspergillus oryzae
}

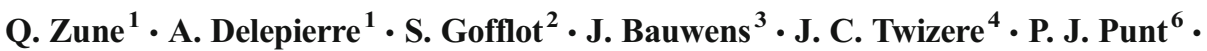

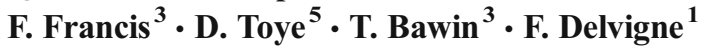

Received: 12 January 2015 /Revised: 2 April 2015 / Accepted: 9 April 2015

(C) Springer-Verlag Berlin Heidelberg 2015

\begin{abstract}
Fungal biofilm is known to promote the excretion of secondary metabolites in accordance with solid-staterelated physiological mechanisms. This work is based on the comparative analysis of classical submerged fermentation with a fungal biofilm reactor for the production of a Gla::green fluorescent protein (GFP) fusion protein by Aspergillus oryzae. The biofilm reactor comprises a metal structured packing allowing the attachment of the fungal biomass. Since the production of the target protein is under the control of the promoter $g l a B$, specifically induced in solid-state fermentation, the biofilm mode of culture is expected to enhance the global productivity. Although production of the target protein was enhanced by using the biofilm mode of culture, we also
\end{abstract}

Electronic supplementary material The online version of this article (doi:10.1007/s00253-015-6608-z) contains supplementary material, which is available to authorized users.

Q. Zune

qzune@ulg.ac.be

F. Delvigne

f.delvigne@ulg.ac.be

1 Microbial Processes and Interactions (MiPI), Gembloux ABT (ULg), 2 Passage des Déportés, 5030 Gembloux, Belgium

2 Unit of Products Transformation Technology, CRAW, 24 Chaussée de Namur, 5030 Gembloux, Belgium

3 Unit of Functional and Evolutionary Entomology, Gembloux ABT (ULg), 2 Passage des Déportés, 5030 Gembloux, Belgium

4 Unit of Cellular and Molecular Biology, Gembloux ABT (ULg), 2 Passage des Déportés, 5030 Gembloux, Belgium

5 Laboratory of Chemical Engineering, ULg, Bâtiment B6c, Sart Tilman, 4000 Liège, Belgium

6 TNO Microbiology \& Systems Biology, 3600 AJ Zeist, The Netherlands found that fusion protein production is also significant when the submerged mode of culture is used. This result is related to high shear stress leading to biomass autolysis and leakage of intracellular fusion protein into the extracellular medium. Moreover, 2-D gel electrophoresis highlights the preservation of fusion protein integrity produced in biofilm conditions. Two fungal biofilm reactor designs were then investigated further, i.e. with full immersion of the packing or with medium recirculation on the packing, and the scale-up potentialities were evaluated. In this context, it has been shown that full immersion of the metal packing in the liquid medium during cultivation allows for a uniform colonization of the packing by the fungal biomass and leads to a better quality of the fusion protein.

Keywords Fungal biofilm · Bioreactor · Scale-up · Recombinant protein

\section{Introduction}

Filamentous fungi are eukaryotic microorganisms commonly used for the production of secondary metabolites such as enzymes or antibiotics. They are also considered as suitable hosts for extracellular recombinant protein production, due to their high secretion potential and their ability to perform posttranslational modifications (Ward 2012). At the industrial scale, several bioreactor designs have been considered for filamentous fungi cultivation based on either submerged or solid-state culture modes. In the submerged culture mode, the filamentous biomass grows as free mycelium suspended in a liquid medium. Depending on different operating parameters, such as inoculum size or agitation rate, the fungal biomass can exhibit different morphologies, ranging from dispersed filaments to spherical masses known as pellets 
(Papagianni 2004). These different morphologies that are exhibited in submerged conditions lead to either an increase of the viscosity of the fermentation broth or a decrease of the diffusion rate. These phenomena lead to the decrease of oxygen and nutrient mass transfer, which in turn lowers the reaction rate and product yield (El-Enshasy 2007). Using the second technique, the solid-state culture mode involves the growth of a fungal biomass on the surface of moist but solid substrates. In this absorptive nutrition mode that is close to that found in the natural environment, the morphological and physiological state of the fungal biomass significantly increases the secretion of proteins and secondary metabolites in comparison with the submerged cultivation mode (Barrios-González 2012). However, large-scale applications are limited due to the appearance of oxygen and nutrient gradients inside the solid mass, as well as difficulties for heat removal and downstream processing operations (Bhargav et al. 2008). A third category of fermentation system based on the formation of a fungal biofilm combines the physiological advantages of solid-state culture and the ease of control of submerged culture operating conditions. The term biofilm is generally used to describe bacterial and yeast communities but has been recently extended to the surface-associated growth of filamentous fungi (Harding et al. 2009). In a biofilm reactor (BfR), filamentous fungal biomass naturally adheres and colonizes the surface of an inert support in contact with a liquid medium (Gamarra et al. 2010). According to Gutiérrez-Correa et al. (2012), this kind of bioreactor is referred as "surface adhesion fermentation". The fungal BfR differs from solidstate fermentation in the use of an inert support and the high water availability provided by the liquid medium flowing across the support's surface. Many examples of secondary metabolite production from filamentous fungi, such as Aspergillus sp. or Trichoderma sp., in a fungal BfR demonstrate higher product yields than submerged cultures (Gutiérrez-Correa et al. 2012). The internal structure of fungal biofilm comprises channels in the hyphal layers that allow fluid circulation and promote a better mass transfer in comparison with the more compact structure of pellets found in a submerged culture (Villena et al. 2010). Moreover, fungal BfRs facilitate reuse of fungal biomass for long-term production and downstream processing operations. The concept of a BfR, mainly used for environmental applications, has been expanded in the field of microbial catalysis for the production of various metabolites, ranging from medium (organic acids, volatile compounds and enzymes) to high-added-value molecules (antibiotics and heterologous proteins) (Cheng et al. 2010; Qureshi et al. 2005). In these bioprocesses, the specific area $\left(\mathrm{m}^{2} / \mathrm{m}^{3}\right)$ provided by the solid support to allow biofilm growth must be as high as possible in order to maximize productivity of the bioreactor. Thus, this is an important parameter in making scale-up procedures as efficient as possible. Many solid supports, such as polyurethane foam (Barrios-González et al.
2008) or a fibrous bed (Talabardon and Yang 2005), have been designed in previous studies for fungal BfRs. This study is focused on the use of a stainless steel structured packing to support fungal biofilm growth. This packing can be used in two operating modes, i.e. totally immersed or aspersed by the liquid medium. The solid support is composed of several corrugated sheets in a staggered arrangement providing high specific area $\left(750 \mathrm{~m}^{2} / \mathrm{m}\right)$ (Aferka et al. 2011). This kind of device was initially developed for the intensification of chemical processes and has been suggested as an efficient strategy for the design of industrial BfRs (Rosche et al. 2009). Although the structure of filamentous fungi biofilms has been previously investigated at the micro-scale level by confocal laser scanning microscopy and cryo-scanning electron microscopy (Villena et al. 2010), the macro-scale characterization of biofilms inside process equipment had not been previously considered. In this work, large-scale X-ray tomography analysis will be used for the non-invasive visualization of the biofilm structure inside the bioreactor (Aferka et al. 2011; Zune et al. 2013). This bioreactor will be used for the production of recombinant protein by Aspergillus oryzae. The strain used contains a genetically encoded fluorescent reporter system under the control of a promoter specifically induced in solid-state medium physiology, pglaB (Ishida et al. 1998, 2000; Te Biesebeke et al. 2002). The reporter gene is a fusion gene including the region encoding an amino acid sequence of a glucoamylase (GlaA) fused with the green fluorescent protein (GFP) sequence, allowing a simple detection and quantification of the fusion protein in the extracellular medium.

\section{Material and methods}

\section{Engineering of the recombinant fungal strain}

A. oryzae ATCC16868pyrG mutant (Te Biesebeke et al. $2005 \mathrm{~b}$ ) was used as the host strain for co-transformation of the desired GFP expression vectors. Plasmid pAB4.1 (Hartingsveldt et al. 1987) containing the Aspergillus niger pyrG mutant was used as the source of the selection marker. The glucoamylase B gene ( $g l a B$ ) was shown to be highly expressed during solid-state cultivation (Te Biesebeke et al. 2005a). Therefore, an expression vector was generated based on gla $B$ expression signals. As a marker gene to monitor glaB gene expression, a gla::GFP fusion gene of $A$. niger was chosen to allow detection of gene expression using mycelial biofilm cultures. The promoter region of the $A$. oryzae glaB gene (GenBank accession AB007825) was amplified by using the forward primer 5'-GTACGCGGCCGCGCAGGAGACC TTTACTTGGCATAG-3' (with the NotI site bold) and the reverse primer 5 '-TTCCCCATGGTGGTGGTGACTTCC AAG-3' (with the $\mathrm{NcoI}$ site bold). For the glaB gene promoter amplification cycling conditions in appropriate buffers 
(dNTPs, $\mathrm{Mg}^{2+}$ and salts), conditions as indicated by the manufacturer (Promega, Leiden, The Netherlands) were as follows: denaturation at $94{ }^{\circ} \mathrm{C}$ for $5 \mathrm{~min}$ followed by 30 cycles of denaturation at $94{ }^{\circ} \mathrm{C}$ for $30 \mathrm{~s}$, annealing at $55^{\circ} \mathrm{C}$ for $30 \mathrm{~s}$ and extension at $72^{\circ} \mathrm{C}$ for $1 \mathrm{~min}$ and a final elongation step carried out at $72{ }^{\circ} \mathrm{C}$ for $10 \mathrm{~min}$. PCR fragments were cloned in a linearized NotI-NcoI (New England Biolabs, Hitchin, UK) pGEMT vector (Promega, Leiden, The Netherlands). From the resulting clones, the cloning of the correct insert sequence was verified by sequence analysis. Subsequently, the $0.6-\mathrm{kb}$ NotI-NcoI glaB promoter fragment was ligated to a $3-\mathrm{kb} N c o \mathrm{I}-$ $X b a \mathrm{I}$ fragment from pAN56-1-pgpd-gla::GFP. The latter is derived from a vector previously described by Gordon et al. (2000) carrying the gla::GFP fusion gene and the $2.5-\mathrm{kb}$ NotI$X b a \mathrm{I}$ vector backbone from pAN56-1 (GenBank accession Z32700). The ligation resulted in pAN56-1-pglaB-gla::GFP. The gla::GFP vector was co-transformed with the pAB4-1 plasmid containing the $A$. niger pyr $G$ auxotrophic selection marker in the $A$. oryzae ATCC16868pyrG protoplasts. Transformants were selected for growth in the absence of uridine. The transformants were analyzed by colony hybridization using a ${ }^{32} \mathrm{P}$-labelled $\operatorname{trpC}$ terminator probe, and one transformant was selected based on its highest hybridization signal. Southern analysis using a GFP probe was carried out to confirm integration of gla::GFP gene copies. To confirm secretion of the Gla::GFP fusion protein, the transformant and its parental host were grown on solid-state cultures for 6 days on pre-treated wheat kernels. Microscopic observation of the moulded kernels revealed clear GFP fluorescence of the Gla::GFP transformant. The secreted proteins were extracted, loaded onto two separate $10 \%$ acrylamide gels and blotted on polyvinylidene fluoride (PVDF) membranes (GE Healthcare, Eindhoven, The Netherlands). The glucoamylase and the GFP were respectively immunodetected with specific antibodies on membrane A and membrane B and revealed with the ECL detection kit (GE Healthcare, Eindhoven, The Netherlands). Results show that multiple high-molecular-weight bands were observed with the GlaA antiserum, whereas with the GFP antiserum, two bands of $>70$ and $23 \mathrm{kDa}$ were observed. These bands most likely represent the Gla::GFP fusion protein and a proteolytically truncated GFP protein.

\section{Inoculum preparation and cultivation medium}

A Petri dish with PDA medium (Merck, Darmstadt, Germany) was inoculated with fungal spores, incubated for 4 days at $30{ }^{\circ} \mathrm{C}$ and stored at $4{ }^{\circ} \mathrm{C}$ for up 2 weeks, before harvest by addition of $10 \mathrm{~mL}$ of peptone water and scraping with a sterile syringe needle. The spores from one Petri dish were counted using a Burker cell in order to inoculate the liquid medium (soluble starch $5 \mathrm{~g} / \mathrm{L}$, casein peptone $5 \mathrm{~g} / \mathrm{L}$, yeast extract $5 \mathrm{~g} / \mathrm{L}$, chloramphenicol $100 \mathrm{mg} / \mathrm{L}$ and one drop of an antifoaming agent KS911) to the target density of 1-2 E+8 spores/L.

\section{Operating conditions}

\section{Shake flask experiments}

In order to get a high-throughput version of the BfR, standard 250 -mL flasks were equipped with support composed of four pieces of corrugated sheets cut from a stainless steel structured packing and put in the bottom (Fig. 1a). The inert support was partially immersed in $100 \mathrm{~mL}$ of liquid medium. After inoculation by spores, each flask was incubated at $30{ }^{\circ} \mathrm{C}$ in an orbital shaker at $130 \mathrm{rpm}$ (rounds per minute).

\section{Fungal BfR}

The fungal BfR is a 2-L stirred tank bioreactor (STR) without its agitation axis (Sartorius, Gottingen, Germany). This has been replaced by a stainless steel structured packing (Sulzer Chemtech, Winterthur, Switzerland) having the function of an inert support with a high specific area $\left(750 \mathrm{~m}^{2} / \mathrm{m}^{3}\right)$. Two operating modes were considered in this work. In the first one,
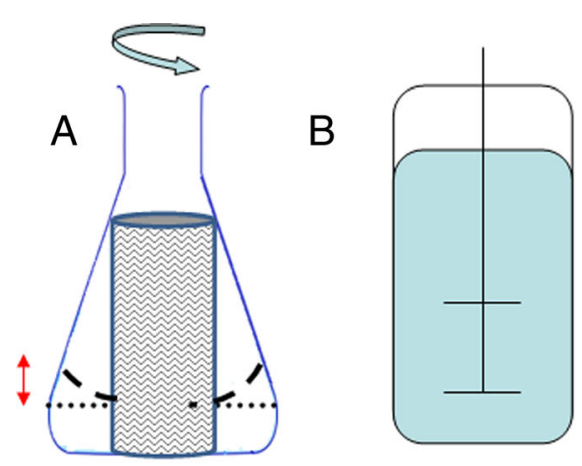

Fig. 1 Scheme of the cultivation systems. a Flask equipped with a piece of structured packing partially immersed in the liquid phase. b Stirred tank bioreactor used for the submerged culture. c Fungal BfR with a
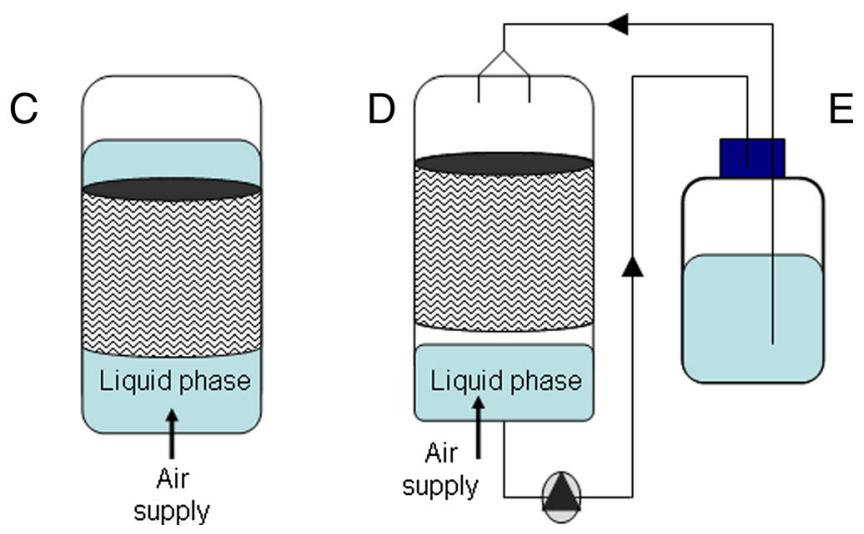

totally immersed support. d Fungal BfR with recirculation of the liquid phase on the support. e Intermediary vessel 
the support was totally immersed in $2 \mathrm{~L}$ of the liquid medium during the entire culture period (Fig. 1c). In the second one, the support was totally immersed in the liquid medium during the first $24 \mathrm{~h}$ of culture (Fig. 1d). Then, a fraction of the liquid phase was transferred into an intermediary vessel (Fig. 1e) in order to perform a continuous recirculation of the liquid on the support by using a peristaltic pump (connections were made with silicone tubing with an internal diameter of $5 \mathrm{~mm}$ ). The recirculated medium was distributed on the metal packing by two holes in the lid of the bioreactor at a flow rate of $18 \mathrm{~L} / \mathrm{h}$. An aeration flow rate of $1 \mathrm{vvm}$ (air volume per liquid volume per minute), temperature of $30^{\circ} \mathrm{C}$ and $\mathrm{pH}$ of 6 were maintained for each fermentation run of $72 \mathrm{~h}$. Fermentation broths were inoculated with the same spore density from the same Petri dish. Table 1 summarizes the culture parameters of the fermentation run in the fungal BfR and STR.

\section{X-ray tomography analysis}

At the end of each fermentation run, stainless steel structured packing was analyzed by X-ray tomography (Laboratory of Chemical Engineering, Liège, Belgium) in order to quantify and visualize biofilm colonization. X-ray tomography is a non-invasive imaging technique allowing visualization of a three-dimensional object. Collected data can be converted to a two-dimensional image corresponding to a given crosssectional area of the metal structured packing. Tomographic measurements were performed on 16 different cross-sectional areas located at different heights (analysis is performed every $5 \mathrm{~mm}$ ). The experimental method for tomographic measurements and subsequent treatment for absorption coefficient processing and image analysis have been previously described (Aferka et al. 2011; Zune et al. 2013).

\section{Biomass quantification}

Determination of the dry biomass in submerged culture was performed in duplicate on $5 \mathrm{~mL}$ of culture medium. The sample was filtered on a $0.45-\mu \mathrm{m}$-mesh filter and amply washed with distilled water in order to remove all soluble matter. Then, a filter was weighed after oven-drying at $110^{\circ} \mathrm{C}$ for $48 \mathrm{~h}$. Dry matter of the fungal biofilm attached to the metal packing was calculated separately by a gravimetric method.
At the end of the culture, the packing was kept out of the bioreactor for $2 \mathrm{~h}$ in order to remove excess liquid before further analysis. A piece of moist fungal biofilm was scraped off the packing and kept in an oven at $110{ }^{\circ} \mathrm{C}$ for $48 \mathrm{~h}$. The weight difference before/after oven-drying allows for calculation of dry matter of the fungal biofilm.

\section{Biochemical analysis}

Supernatant of the liquid phase was sampled during the culture in order to follow kinetic parameters. Each collected sample was filtered on a $0.20-\mu \mathrm{m}$ syringe filter mesh and stored at $-20{ }^{\circ} \mathrm{C}$ before further analysis. A cocktail of protease inhibitors (Roche Diagnostics, Vilvoorde, Belgium) was added to samples used for Western blot and proteomic analysis.

\section{pH measurement}

The evolution of the $\mathrm{pH}$ was monitored in the liquid medium of flask-scale cultures. Each collected sample's pH was measured with a pH meter (Microprocessor, Hanna instruments, Temse, Belgium) immediately after sampling.

\section{Residual starch concentration and enzymatic activity of $\alpha$-amylase}

A spectrometric method based on the blue starch-iodine complex was used to determine residual starch in the culture supernatant. Firstly, $100 \mu \mathrm{L}$ of culture supernatant was mixed and incubated for 10 min with $4.9 \mathrm{~mL}$ of a reagent solution composed of $0.04 \% \mathrm{KI}(w / v)$ and $0.1 \mathrm{M} \mathrm{HCl}$, before reading absorbance at $580 \mathrm{~nm}$. The $\alpha$-amylase enzymatic activity was quantified by a standard spectrometric method (DNS) based on the assay of glucose and maltose amounts produced by enzymatic hydrolysis of soluble starch. A first test tube (T1) composed of $500 \mu \mathrm{L}$ of a buffer solution $\left(0.02 \mathrm{M} \mathrm{NaH}_{2} \mathrm{PO}_{4}\right.$. $2 \mathrm{H}_{2} \mathrm{O}$ and $\left.0.006 \mathrm{M} \mathrm{NaCl}, \mathrm{pH} 6.9\right)$ was mixed with $500 \mu \mathrm{L}$ of $1 \%$ soluble starch solution $(w / v)$. A second test tube (T2) composed of $500 \mu \mathrm{L}$ of a diluted sample was mixed with $500 \mu \mathrm{L}$ of buffer solution. A third test tube (T3) containing $500 \mu \mathrm{L}$ of the same diluted sample was mixed with $500 \mu \mathrm{L}$ of $1 \%$ soluble starch solution $(w / v)$ and incubated for $10 \mathrm{~min}$ at $40{ }^{\circ} \mathrm{C}$. Starch hydrolysis was stopped by adding $3 \mathrm{~mL}$ of a

Table 1 Overview of the operating parameters used for the cultivation tests carried out in stirred tank (STR) and biofilm reactors (BfR)

\begin{tabular}{lllllllr}
\hline Culture mode & $\mathrm{pH}$ & $\begin{array}{l}\text { Temperature } \\
\left({ }^{\circ} \mathrm{C}\right)\end{array}$ & Aeration $(\mathrm{vvm})$ & $\begin{array}{l}\text { Agitation } \\
(\mathrm{rpm})\end{array}$ & $\begin{array}{l}\text { Recirculation } \\
\text { flow rate }(\mathrm{L} / \mathrm{h})\end{array}$ & Specific area $\left(\mathrm{cm}^{2}\right)$ & $\begin{array}{l}V_{\text {initial }}(\mathrm{L}) \\
\text { Inoculum } \\
(\mathrm{spores} / \mathrm{L})\end{array}$ \\
\hline STR1 & 6 & 30 & 0.5 & 800 & $/$ & $/$ & 1.1 \\
STR2 & 6 & 30 & 0.5 & 200 & $/$ & $/$ & $1-2 \mathrm{E}+08$ \\
Immersed BfR & 6 & 30 & 1 & $/$ & $/$ & 6600 & $1-2 \mathrm{E}+08$ \\
Aspersed BfR & 6 & 30 & 1 & $/$ & 18 & 6600 & $1-2 \mathrm{E}+08$ \\
\hline
\end{tabular}


DNS solution to each test tube (per litre, $10 \mathrm{~g} \mathrm{NaOH}, 4 \mathrm{~g}$ phenol, $10 \mathrm{~g}$ DNS, $0.5 \mathrm{~g} \mathrm{Na}_{2} \mathrm{SO}_{3}$ and $268.5 \mathrm{~g}$ "sel de Rochelle") followed by $5 \mathrm{~min}$ of incubation at $95{ }^{\circ} \mathrm{C}$. Then, $10 \mathrm{~mL}$ of distilled water was added to each tube before reading absorbance at $550 \mathrm{~nm}$. One $\alpha$-amylase activity unit (UA) equals $1 \mu \mathrm{mol}$ of released glucose $\mathrm{mL}^{-1} \mathrm{~min}^{-1}$. The amount of glucose released was obtained by subtracting the absorbance intensities: Abs (T3)-Abs (T2)-Abs (T1). Each measurement was performed in triplicate.

\section{Gla::GFP fusion protein detection and quantification}

Total extracellular protein content was quantified with BioRad DC Protein Assay (Bio-Rad, Hercules, CA). Quantification and detection of Gla::GFP in the extracellular medium was based on the intensity of green fluorescence and Western blot analysis. Fluorescence intensity was measured with a spectrofluorimeter (Victor ${ }^{3} \mathrm{~V}$ Wallac, PerkinElmer, Zaventem, Belgium) in samples of $200 \mu \mathrm{L}$ added to a 96microwell black plate. For Western blot analysis, proteins from each supernatant sample were precipitated in $25 \%$ trichloroacetic acid and were twofold concentrated after pellet resuspension in a $0.2-\mathrm{M} \mathrm{NaOH}$ solution. Proteins trapped in the fungal biofilm matrix and mycelial pellet (attached outside of the cell wall) were also recovered and subjected to Western blot analysis. A sample of biofilm/mycelial pellet was washed with PBS ( $\mathrm{pH}$ 7.2) and incubated in an extraction buffer $(0.05 \%$ sodium dodecyl sulfate (SDS) in $50 \mathrm{mM}$ sodium phosphate buffer, $\mathrm{pH} 7$ ) at $95{ }^{\circ} \mathrm{C}$ for $5 \mathrm{~min}$. Then, the sample was intensely vortexed and filtered (using a $0.2-\mu \mathrm{m}$ mesh) in order to collect the supernatant. Proteins were then recovered by $25 \%$ trichloroacetic acid precipitation and $0.2 \mathrm{M} \mathrm{NaOH}$ resuspension. Samples were separated on a $30 \%$ polyacrylamide gel (with ten wells) respecting standard SDS-PAGE procedures. In order to assess the relative abundance of the Gla::GFP fusion protein in the total extracellular protein content, we loaded the same protein amount $(25 \mu \mathrm{g})$. After SDSPAGE, proteins were transferred on PVDF membranes (GE Healthcare, Zaventem, Belgium). Specific bands corresponding to GFP and the fusion protein were immunodetected by an antibody anti-GFP and revealed with the ECL kit (GE Healthcare, Zaventem, Belgium).

\section{2-D gel electrophoresis of the extracellular proteome}

The extracellular proteome of the last sample from each culture condition was analyzed using 2-D gel electrophoresis. Culture supernatant was filtered on a $0.20-\mu \mathrm{m}$ mesh, and protease activity was halted by adding a cocktail of protease inhibitors (Roche Diagnostics, Vilvoorde, Belgium). Proteins were precipitated from samples using the 2-D cleanup kit (GE Healthcare, Zaventem, Belgium) and resuspended in an $8 \mathrm{M}$ urea-2 $\mathrm{M}$ thiourea buffer solution. The volume of the total protein sample was adjusted to $450 \mu \mathrm{L}$ with a rehydration buffer ( $8 \mathrm{M}$ urea-2 $\mathrm{M}$ thiourea buffer solution with $0.8 \%$ IPG and $0.4 \%$ DTT) and loaded onto $\mathrm{pH} \mathrm{3-10} \mathrm{strips}(24 \mathrm{~cm}$, linear) for iso-electrofocalization (IEF1). IEF1 and SDSPAGE were carried out following established procedures described by (Bauwens et al. 2013). It must be noted that overexpressed proteins from the aspersed BfR, especially from the glucoamylase family, tended to disrupt migration of proteins of similar iso-electric points and lower molecular weights when sample loading exceeded $50 \mu \mathrm{g}$ of protein. Thus, a 2D gel electrophoresis separated $30 \mu \mathrm{g}$ of proteins labelled with a fluorochrome (CyDye, GE Healthcare, Zaventem, Belgium) for image analysis and subsequent quantification for the first replicate. For the second replicate, $400 \mu \mathrm{g}$ of proteins from the immersed BfR and the STR was separated using 2-D gel electrophoresis. The resulting 2-D gel was stained with Coomassie Brilliant Blue (CBB) for mass spectrometry analysis and spot quantification. All gels were scanned with an Ettan DIGE Imager (GE Healthcare, Zaventem, Belgium).

\section{Protein identification and quantification}

For protein identification, spots resulting from CBB gel staining were excised with an Ettan Spot Picker (GE Healthcare, Zaventem, Belgium) and placed in a 96-microwell plate filled with $50 \mu \mathrm{L}$ of Milli-Q water. All visible spots were picked after CBB gel staining for each condition. The protocol for sample preparation for the MALDI-TOF-MS experiment was described by Bauwens et al. (2013). Peptide mass fingerprinting was used to query non-redundant NCBI databases (http:// www.ncbi.nlm.nih.gov/protein) (fungi taxonomy). Protein identification was considered positive if a mascot sore of at least 50 with 100 ppm of mass error tolerance in MS was achieved.

Protein quantification was performed on the basis of spot intensities by using Progenesis SameSpots Software (Nonlinear Dynamics, Newcastle upon Tyne, UK). The ratios of normalized volumes from the same spots were calculated in order to assess levels of protein excretion between biofilm and submerged culture conditions.

\section{Results}

Preliminary screening of the growth and excretion abilities of fungal biofilms attached to metal structured packing

The fermentation kinetic of $A$. oryzae under biofilm conditions was first investigated in flask scale with and without metal structured packing. The presence of soluble starch in the liquid medium involves a first step of hydrolysis in glucose monomers in order to allow carbon source assimilation, followed by a second step of glucose consumption inducing 
exponential growth phase of the mycelium. Starch and glucose consumption rates in the extracellular medium are higher in the flask equipped with the metal packing (Fig. 2a, b).

Acidification of the extracellular medium resulting from carbon source consumption is lower when considering biofilm conditions (i.e. flasks with metal structured packing) with a $\mathrm{pH}$ reaching a minimum at 6.63 against 5.66 in the case of submerged conditions (i.e. flasks with no packing) (Fig. 2c). However, the rise of $\mathrm{pH}$ is faster in biofilm conditions and quickly reaches alkaline $\mathrm{pH}$ values after $50 \mathrm{~h}$ of culture. These conditions can affect the quality of the fusion protein and the resulting quantification based on green fluorescence intensity of the extracellular medium. Based on these fluorescence measurements, the fusion protein production starts when glucose depletion occurs and reaches a maximum after $122 \mathrm{~h}$ of culture (Fig. 2d) and seems to be very similar between submerged and biofilm cultures. These observations must be carefully interpreted because significant medium alkalinization could alter fluorescence of the fusion protein.

According to this observation, the presence of the fusion protein in the extracellular medium was further determined by Western blot analysis (Fig. 3). Several bands were detected for the two operating conditions, suggesting that the stability of the fusion protein was impaired by the culture conditions. Indeed, secretion under biofilm and submerged conditions seems to involve several biochemical modifications including proteolytic leakage and association of fusion protein products.
The first band at $27 \mathrm{kDa}$ corresponds to a proteolytically truncated GFP, a second band at $>70 \mathrm{kDa}$ corresponds to the fusion protein Gla::GFP and a third at $>100 \mathrm{kDa}$ could correspond to the association of several fusion protein products (GFP tetramer with a molecular weight of $108 \mathrm{kDa}$ ). The bands corresponding to the fusion protein Gla::GFP have been detected between the 69th and 122nd hours of culture, as previously observed by fluorescence measurements. Bands observed in the submerged conditions are thicker than those of biofilm conditions, but this result has to be carefully considered since glycosylation could alter the sensitivity of the immunodetection (Seferian et al. 2008). Moreover, this observation also indicates that fusion protein synthesis occurs in submerged culture conditions, despite the use of the glaB promoter. The latter has been described as a promoter specifically induced in solid-state conditions (Ishida et al. 1998). Observation of mycelial pellet and fungal biofilm by fluorescence microscopy indicates that fluorescent fusion proteins can be trapped within the biofilm matrix (results not shown). This observation was further confirmed by Western blot analysis (Fig. 3) carried out on the protein fraction extracted from the mycelium pellet and the biofilm matrix (see "Material and methods" section). These first results highlight that operating conditions have a significant impact on the quality of the fusion protein. These phenomena will then be further investigated in a bioreactor with $\mathrm{pH}$ control and analysis performed by 2-D gel electrophoresis.
A

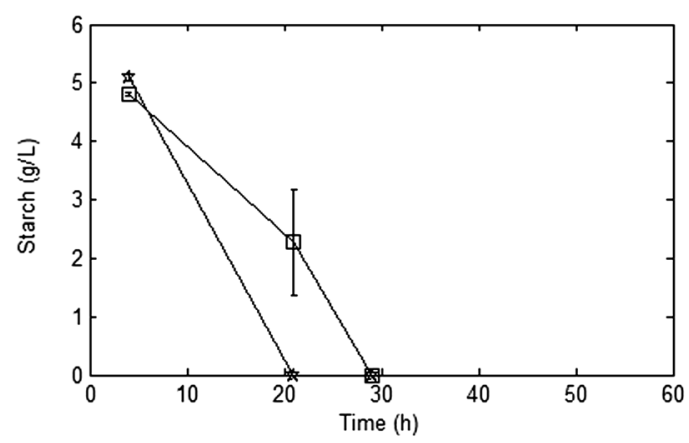

C

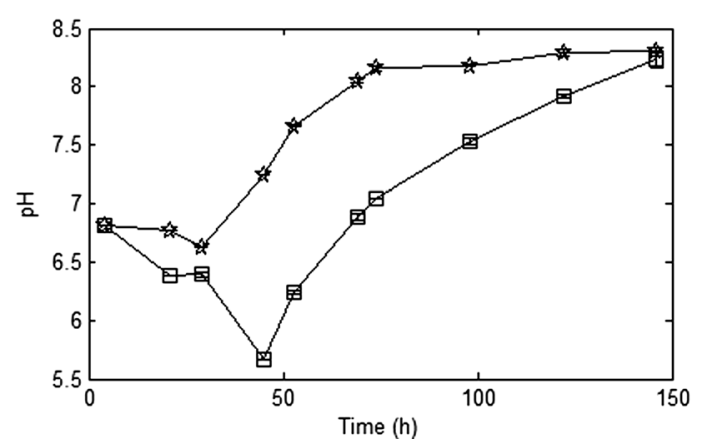

B
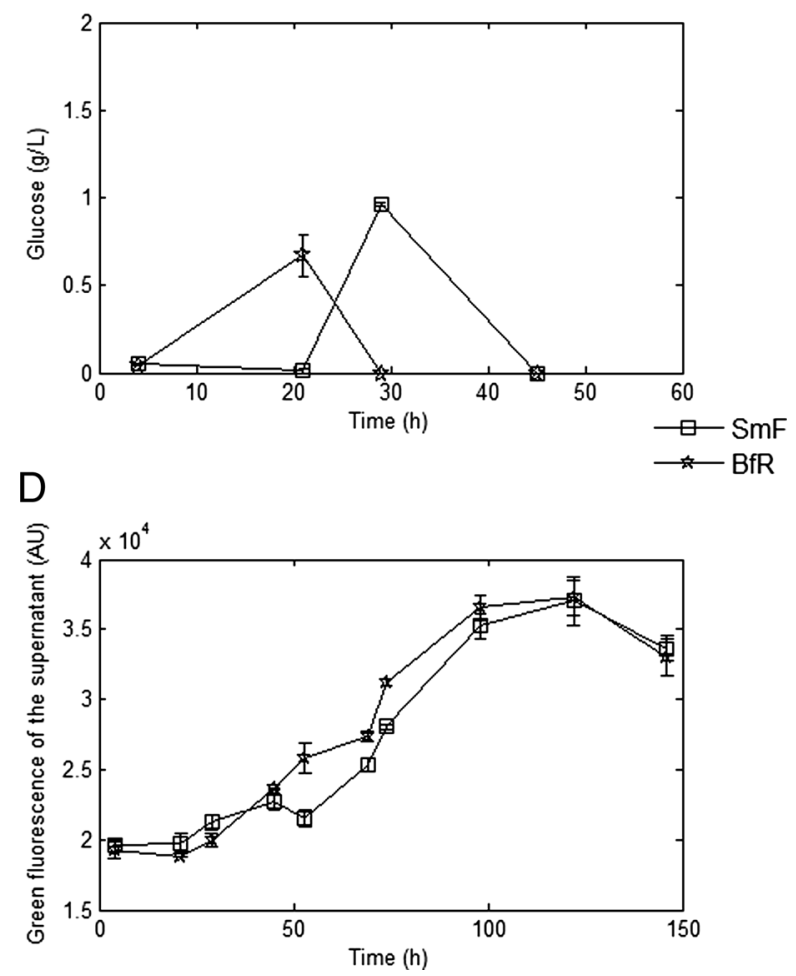

Fig. 2 Carbon source consumption (a, b), pH evolution (c) and green fluorescence intensity (d) in the extracellular medium during cultures carried out in shake flasks in biofilm or submerged conditions 
Fig. 3 Western blot analysis of the fusion protein GLA::GFP in flask-scale cultures. Fusion protein localized in extracellular medium was quantified after 69 and $122 \mathrm{~h}$ of culture. Fusion protein being attached to the biofilm matrix/pellet was only detected at the end of the fermentation

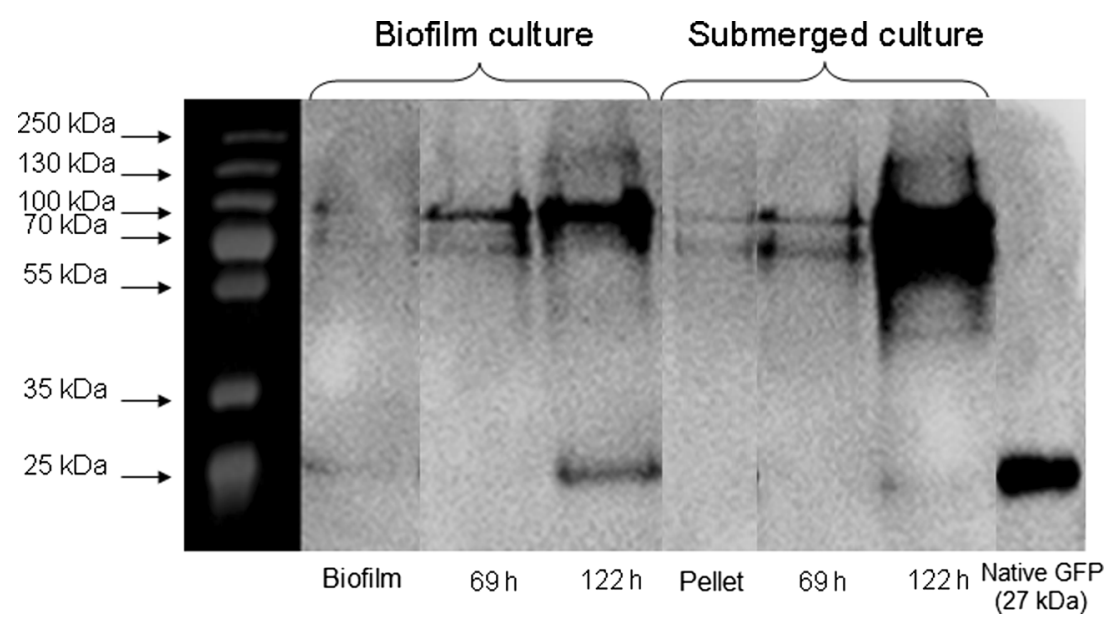

\section{Colonization efficiency in shake flask conditions}

After the inoculation step, spores quickly adhere to the metal surface immersed in the liquid medium, since spores cannot be seen in the liquid medium after $6 \mathrm{~h}$ of culture and growth of free mycelial pellets is not observed in the liquid medium throughout the culture period (results not shown). Spore germination is then followed by a first step of colonization of the whole area provided by the packing, followed by a second step of thickness growth of the fungal biofilm (Harding et al. 2009). Low shear forces from orbital shaking prevent the detachment of the fungal biomass (Fig. 4a). Under these conditions, the low viscosity of the liquid phase improves oxygen transfer rate at the beginning of the fermentation and can explain the higher rate of carbon source consumption in biofilm conditions. Liquid oscillations induced by orbital shaking lead to the alternate exposure of a fraction of the fungal biofilm to gas and liquid phases (Fig. 4a). After removing the culture supernatant of flasks equipped with metal packing, the fungal biofilm attached to the support exhibited an average dry matter of $2.16 \pm 0.25 \mathrm{~g}$ of cells per $100 \mathrm{~g}$ of biofilm. The high water content explains why the residual volume is lower in the flask equipped with the metal packing. Dry matter of the fungal biofilm encompasses a non-negligible presence of insoluble exopolymeric substances (EPS) leading to a slight over-estimation of bioconversion yield in biofilm conditions $(0.45 \pm 0.02 \mathrm{~g}$ of dry biomass matter/g of carbon source against $0.44 \pm 0.01 \mathrm{~g}$ of dry biomass matter/g of carbon source in submerged conditions).

The initial amount of soluble starch influences the colonization of the packing by the fungal biofilm (Fig. 4b). X-ray tomography analysis of cross-sectional areas of the colonized
Fig. 4 Fungal colonization of metal structured packing in flask scale. a Picture of metal packing covered with the two kinds of fungal layers, i.e. fully or alternatively immersed biofilm. b Reconstructed images from X-ray tomography analysis of a crosssectional area of metal packing colonized by fungal biofilm (white pixels) with initial starch concentrations of 1, 10,20 and $40 \mathrm{~g} / \mathrm{L}$. Presence of fungal biomass in the liquid phase is observed $(+)$ or not $(-)$ according to the initial substrate concentration
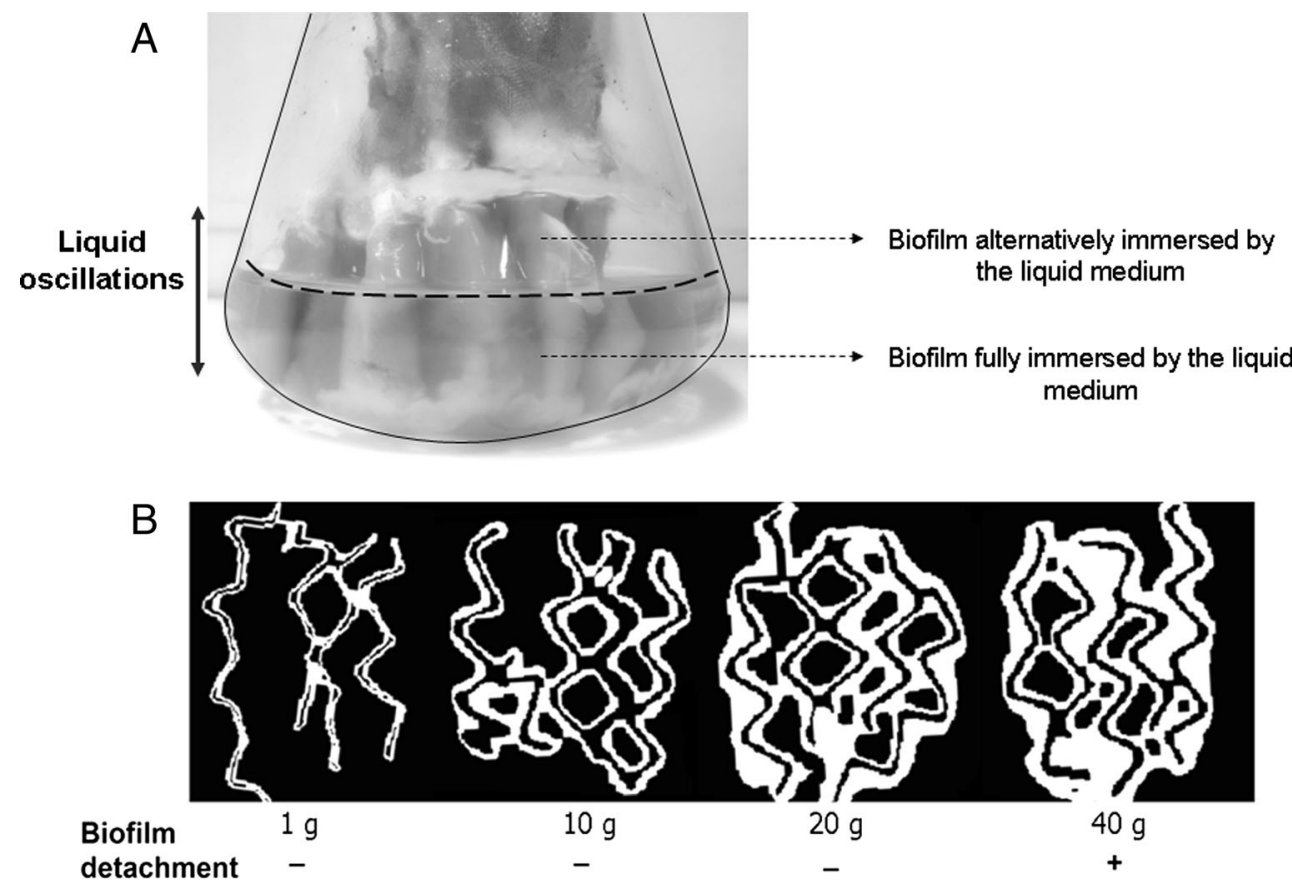
A

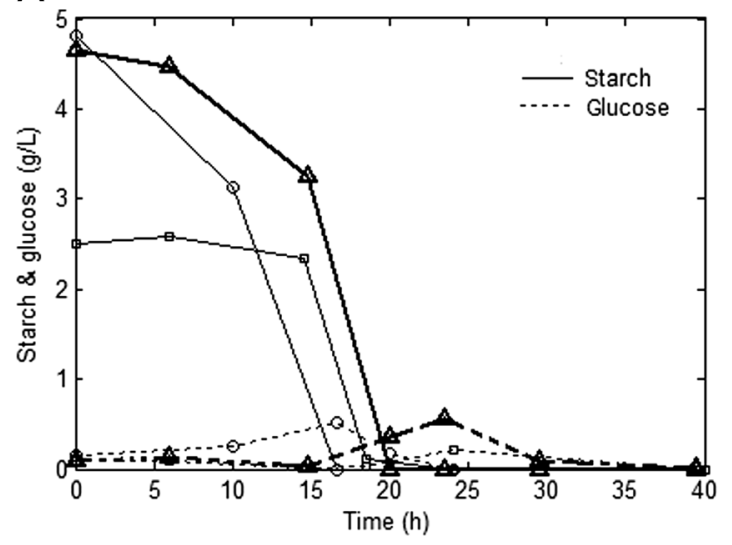

C

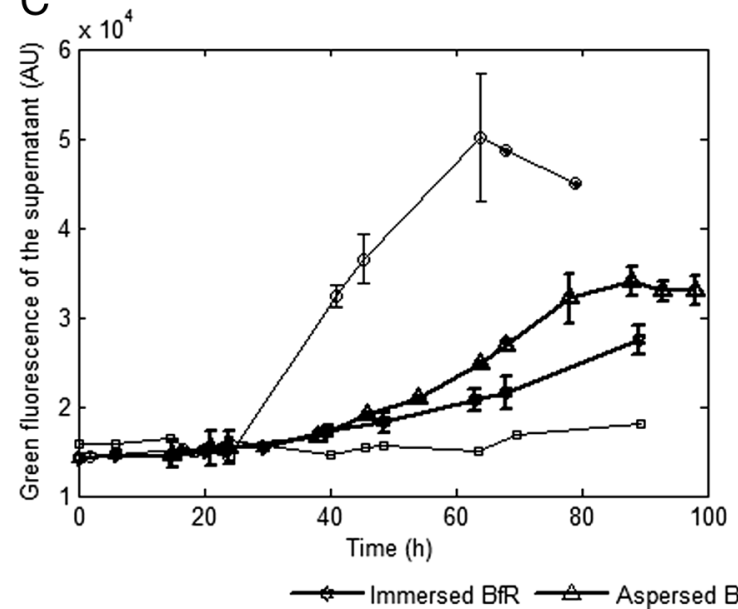

B

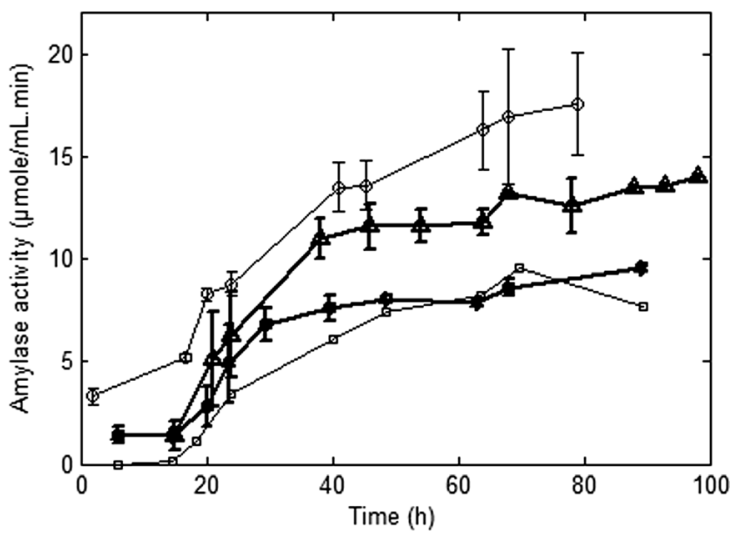

D

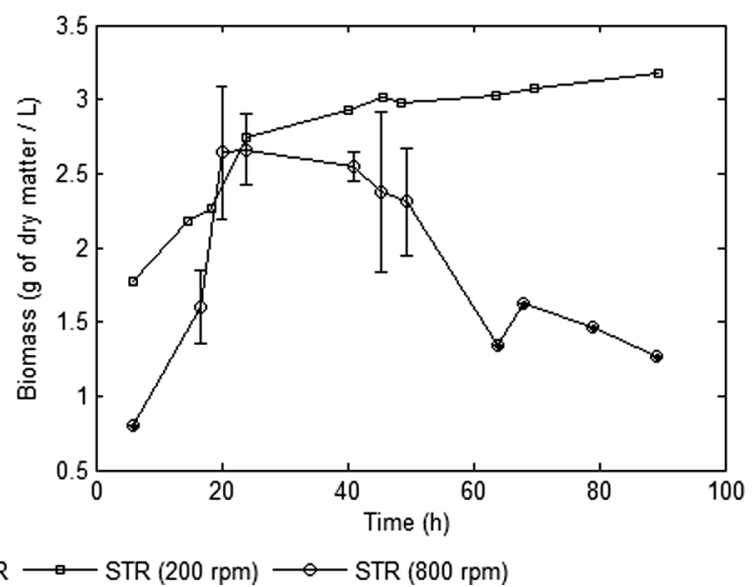

Fig. 5 a Consumption of carbon sources (starch and glucose). b Enzymatic activity of $\alpha$-amylase in the extracellular medium. $\mathbf{c}$ Recombinant protein GLA::GFP quantification in extracellular medium based on fluorescence intensity. $\mathbf{d}$ Dry matter quantification in submerged cultures

support shows that the thickness of the fungal biofilm covering the support is proportional to the initial amount of starch. Concentrations higher than $20 \mathrm{~g} / \mathrm{L}$ cause fungal biomass clogging between the corrugated sheets of the packing and lead to a partial leakage of fungal biomass towards the liquid phase (Fig. 4b). This observation suggests that an optimal soluble starch concentration should be defined as a function of the specific dimensions of corrugated sheets in order to avoid clogging. This latter phenomenon could affect performance of the mass transfer, e.g. fusion protein recovery in the extracellular medium.

\section{The effect of bioreactor operating conditions}

The production of the fusion protein has been performed in controlled conditions with two BfR configurations designed on the basis of the results obtained by the shake flasks. The first one, i.e. immersed BfR, has the fungal biofilm area totally immersed by the liquid medium. The second one, called aspersed BfR, periodically immerses the biofilm area by liquid recirculation on the metal packing. Submerged conditions in a classical stirred tank bioreactor (STR) were also considered as a control with two agitation rates, i.e. either a low (200 rpm) or high $(800 \mathrm{rpm})$ stirrer rate. Starch and glucose consumptions are faster in STR conditions (Fig. 5a). Biomass growth is only quantified in STR since all fungal biofilm in a BfR is attached to the support and cannot be sampled during the culture. In the presence of starch, synthesis of $\alpha$-amylase and glucoamylase enzymes is strongly activated and constitutes the major fraction of extracellular proteins found in the culture supernatant. Accordingly, protein secretion can be assessed by quantifying $\alpha$-amylase activity in the culture supernatant. Enzyme activity can be observed upon starch depletion in each culture condition, and the strongest rate of increase occurs in the $800 \mathrm{rpm}$ STR and the aspersed BfR. On the other hand, the immersed BfR and the $200 \mathrm{rpm}$ STR exhibit only a slight increase in enzymatic activity (Fig. 5b). Quantification of the total proteins secreted by the fungal biomass confirms our previous observations, with 72.2 and $38.2 \mathrm{mg}$ of proteins $/ \mathrm{mg}$ of dry mycelium in 800 and $200 \mathrm{rpm}$ STR, respectively. These values reach 61 and $40.4 \mathrm{mg}$ of proteins $/ \mathrm{mg}$ of dry mycelium in aspersed and immersed conditions, respectively. Green fluorescence of the culture supernatant follows the same trend as that displayed by the $\alpha$-amylase enzymatic activity 
(Fig. 5c). Surprisingly, the fusion protein is produced earlier and in larger amounts in $800 \mathrm{rpm}$ STR than in biofilm conditions. However, the amount of biomass sharply decreases after $40 \mathrm{~h}$ of culture in $800 \mathrm{rpm}$ STR (Fig. 5d). Excretion of the fusion protein is not observed in $200 \mathrm{rpm}$ STR, suggesting that the shear rate is implied in the release of this protein to the extracellular medium.

\section{Impact of bioreactor operating conditions on the secretion profile}

\section{1-D gel characterization}

In addition to the fluorescence measurements, the quality of the fusion protein was assessed by Western blot analysis using the same amount of protein $(25 \mu \mathrm{g})$. The presence of the fusion protein has been observed for each culture condition. The characteristic bands at $>70 \mathrm{kDa}$ (fusion protein) and $27 \mathrm{kDa}$ (truncated GFP) appear as was previously observed in the flask-scale experiments (Fig. 6a). These bands exhibit different intensities as a function of the bioreactor operating conditions. There were no $27-\mathrm{kDa}$ bands detected in the immersed BfR or $200 \mathrm{rpm}$ STR, indicating a good quality of the fusion protein. This is not the case in aspersed BfR and $800 \mathrm{rpm}$ STR, where products of alteration of the fusion
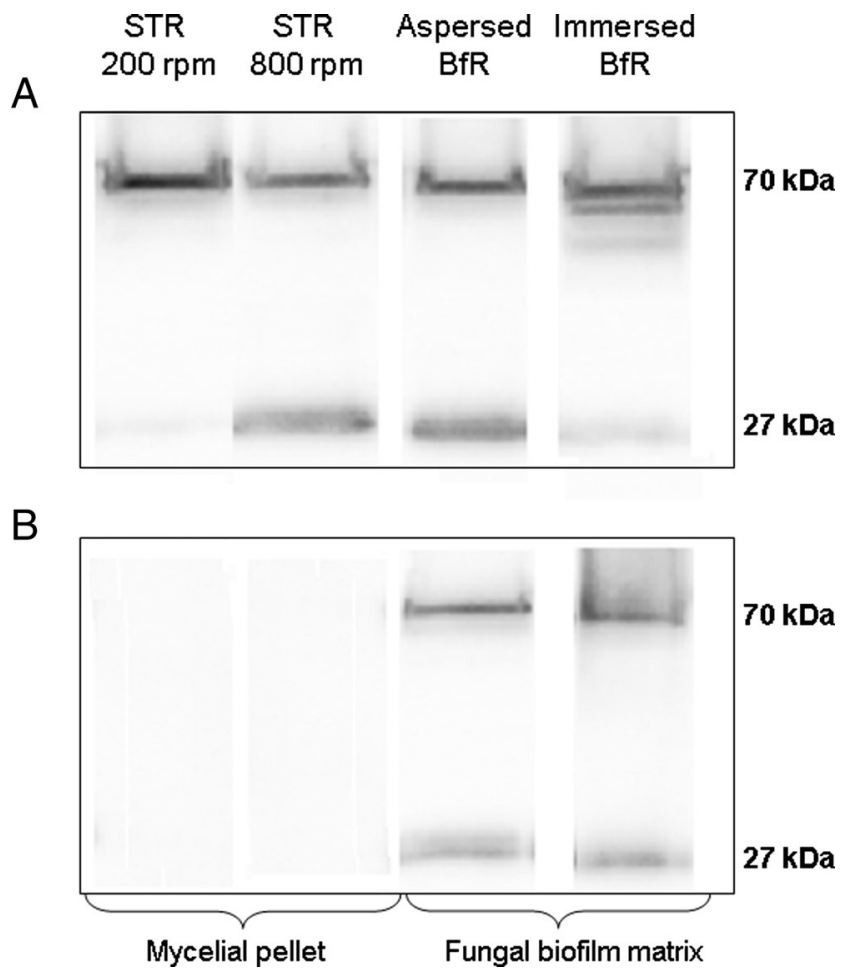

Fig. 6 Western blot analysis of the fusion protein performed with the same loading rate $(25 \mu \mathrm{g})$ for each culture condition after 5 days of culture. a Western blot analysis of the fusion protein in the extracellular medium. b Western blot analysis of the fusion protein trapped in the mycelial pellet and biofilm matrix protein have been observed. Secretion of the fusion protein into the extracellular medium involves passage through the cell wall and the biofilm matrix. Observations of the mycelial pellet and fungal biofilm under fluorescence microscopy reveal fluorescence intensities concentrated in the area of the hyphal cell wall at the tips of growing hyphae (results not shown). A Western blot analysis performed with an extract of proteins from the fungal biofilm matrix from immersed and aspersed BfR shows the presence of the fusion protein (Fig. 6b). This fraction of fusion protein remained trapped in the biofilm matrix. On the other hand, the same protocol of extraction applied to the mycelial pellet in submerged conditions does not allow the detection of the fusion protein.

\section{2-D gel characterization}

Further analysis of extracellular proteome with 2-D gel electrophoresis supports the observations obtained from 1-D gel electrophoresis and gives additional insights about the protein quality and secretion pathways for each culture condition. Upon CyDye labelling (see Fig. S1 in the supplementary material), the expression level of proteins has been compared between each culture condition. In parallel, preparative 2-D gel electrophoresis with CBB straining was carried out and led to the detection of 21 major spots that were picked for MALD I-TOF/MS identification and quantification (see Table S1 in the supplementary material). The majority of the extracellular proteins have an isoelectric point (Ip) between 4 and 6 and a molecular weight (MW) greater than $15 \mathrm{kDa}$. The spots of low MWs observed in labelled CyDye gels represent protein fragments or polypeptides resulting from proteolysis. Among the 21 spots identified by mass spectrometry, four families of enzymes were expressed at different levels in each culture condition, i.e. proteases, polysaccharide hydrolases, glycosyl hydrolases and oxyreductases. The Gla::GFP fusion protein has been identified, as well as additional spots corresponding to the truncated GFP released after its degradation. The extracellular proteomes have been compared between each bioreactor operating condition (Fig. 7) on the basis of supernatant samples taken after 5 days of culture.

Quality assessment of the fusion protein (Fig. 7a) The fusion protein was identified for all the operating conditions tested and exhibited different molecular forms. Indeed, two spots corresponding to the native form of the fusion protein were found, along with four spots corresponding to ::GFP and two spots corresponding to truncated Gla:: released by proteolysis.

Protease secretion (Fig. 7b) Three main proteases have been identified in the extracellular medium: the alkaline protease AlpA (oryzin), the leucine aminopeptidase LapA and a deuterolysin (neutral protease). The presence of aligned spots 

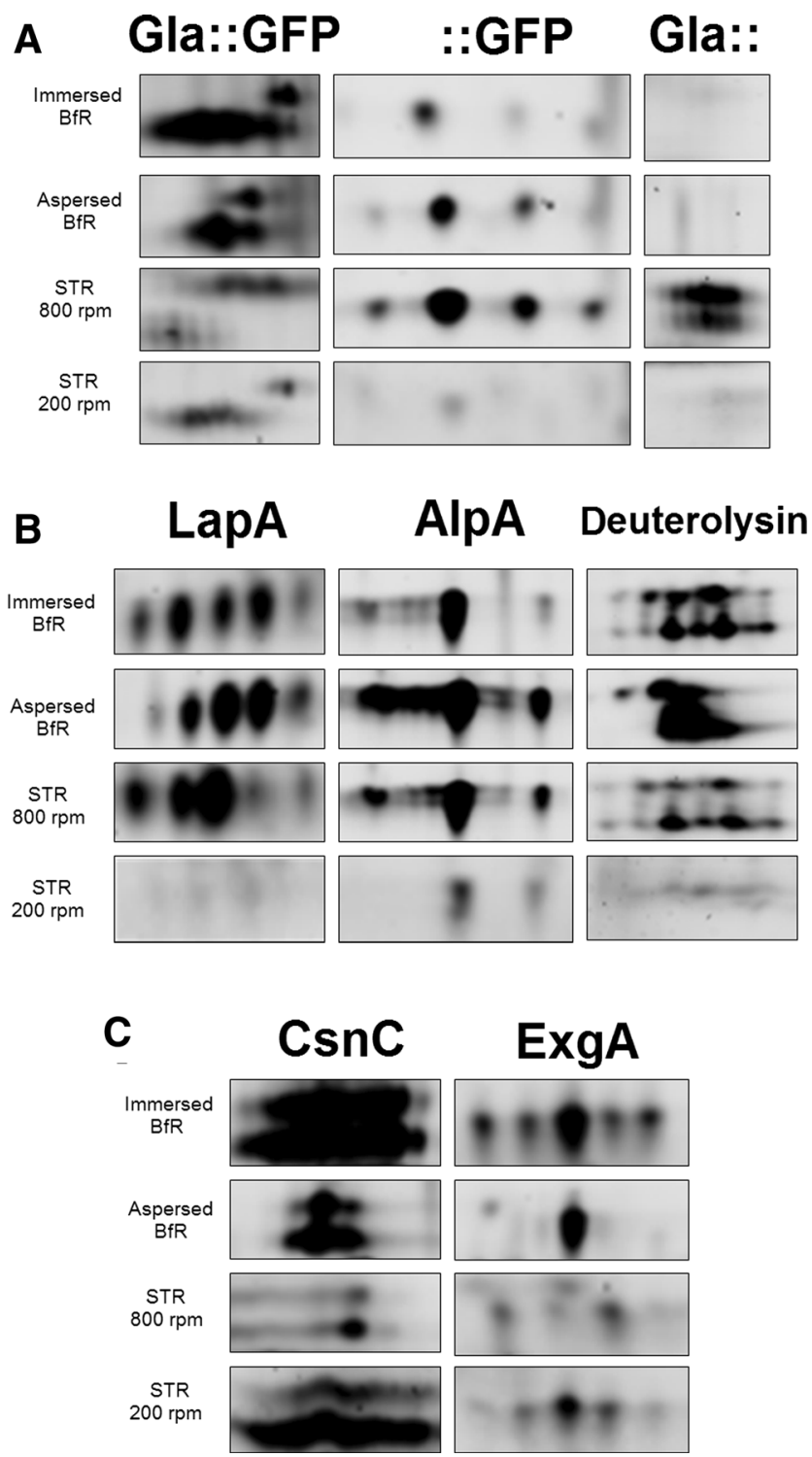

Fig. 7 Spot pattern relative to the comparative extracellular proteome obtained by 2-D gel electrophoresis (CyDye labelling). a Fusion protein. b Alkaline protease. c Specific proteins secreted in solid-state conditions (see 2-D gels and spot identifications in additional results given in Online Resource 1)

of different Ips suggests that these proteases display different phosphorylation degrees or glycosylation levels (glycoform). These different forms can be related to a variability of posttranslational modification pathways involved in protein secretion.

\section{Characteristic proteins secreted in biofilms conditions} (Fig. 7c). Among the proteins mainly secreted in the aspersed and immersed BfRs, we observed large quantities of chitosanase $(\mathrm{CsnC})$ and exo-glucanase $(\operatorname{ExgA})$. The chitosanase CsnC catalyzes the cleavage of chitosan, the deacetylated form of the chitin polymer, a component of fungal cell walls (Sugita et al. 2012). The exo-glucanase (ExgA) is responsible for the hydrolysis of the glucosidic bond found in $\beta$-1-3-glucan, a component of fungal cell walls. This protein is particularly interesting, since its secretion is associated with growth on a solid surface (Tamano et al. 2007). The synthesis of ExgA and CsnC in biofilm conditions could be involved in EPS matrix hydrolysis and cell wall degradation occurring when nutrients are depleted towards the end of the culture.

\section{Colonization efficiency between aspersed and immersed BfRs}

Significant differences between the aspersed and immersed modes of BfR have been observed, and large-scale X-ray tomography was used in order to quantify these differences. The first $24 \mathrm{~h}$ of culture was performed by considering the total immersion of the packing in the liquid phase for the two modes of cultures in BfR. Indeed, total immersion of the packing in the liquid medium promotes spore adhesion and causes germination in a few hours. During the whole cultivation period, the liquid phase is free of biomass (with the substrate concentration considered for the bioreactor tests as previously investigated). When considering the aspersed mode of BfR, $80 \%$ of the liquid phase is transferred to a buffer vessel after $24 \mathrm{~h}$ of culture. The transferred liquid phase is then recirculated on the packing. Liquid distribution is not homogeneous and induces preferential flow paths inside the support leading to spatially localized conidiation on the section of the corrugated sheets that are less fed with the liquid phase. The fungal biofilm distribution can be visualized inside the structured packing by the non-invasive imaging technique of X-ray tomography. The reconstructed image from a cross-sectional area located in the middle of the packing height in the immersed BfR (Fig. 8a, b) shows an equally distributed biofilm of constant thickness across the whole cross-sectional surface provided by the support. At an identical height, a crosssectional area of the packing in the aspersed BfR reveals heterogeneous biofilm distribution with a globally thinner biofilm than that observed for the immersed BfR. Evolution of biofilm surface per cross-sectional area along the height of the packing is almost constant for the immersed BfR. On the other hand, this value increases from the upper section towards the bottom of the support in the case of the aspersed BfR (Fig. 8c), resulting in a conical shape of biofilm distribution. Dry matter of the fungal biofilm at the end of the culture is slightly higher in the aspersed BfR $(2.96 \pm 0.61 \%)$ than in the immersed BfR $(2.60 \pm 0.63 \%)$, but bioconversion yields $(\mathrm{Yx} / \mathrm{s})$ are similar and close to 0.5 .

\section{Discussion}

The development of specific cultivation devices promoting the formation of fungal biofilm is of high interest for the 
A

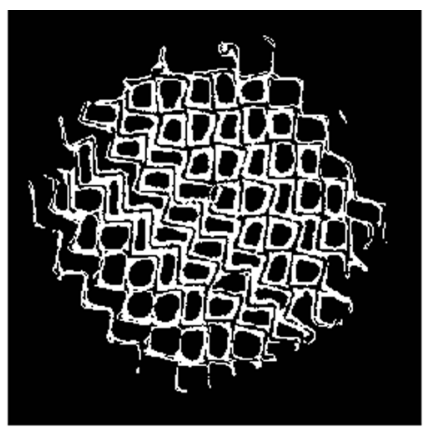

B

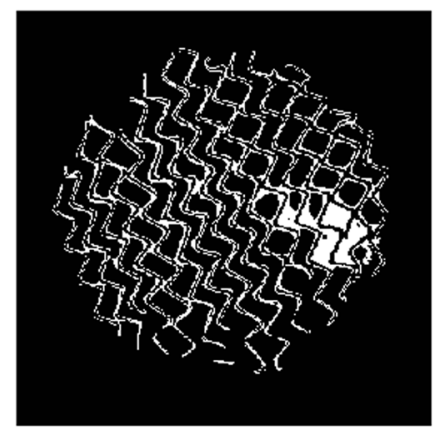

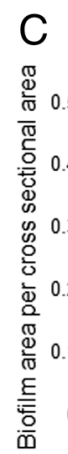
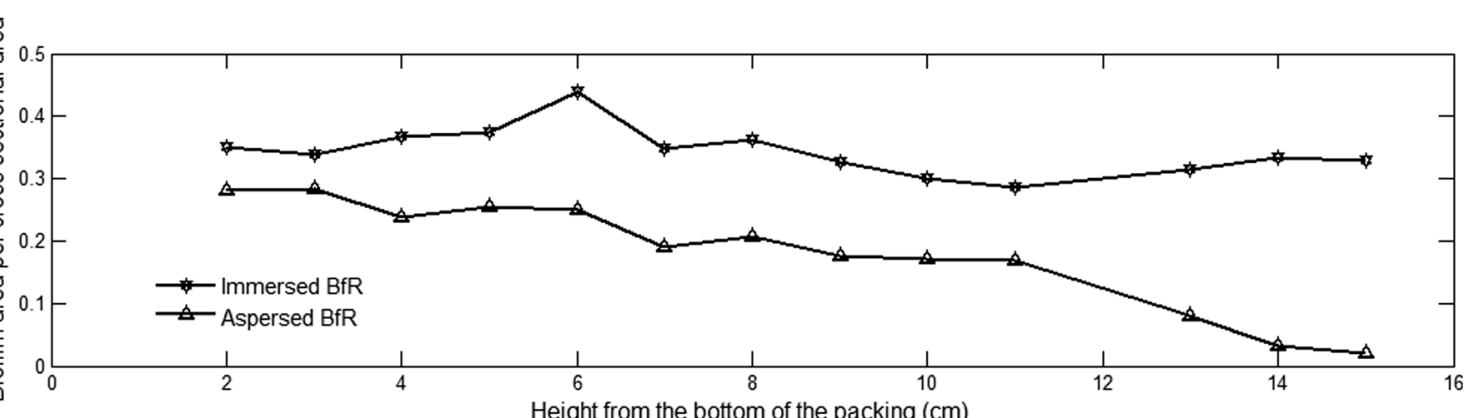

Height from the bottom of the packing $(\mathrm{cm})$

Fig. 8 Visualization of fungal biofilm distribution (white pixels in $\mathbf{a}, \mathbf{b}$ ) inside the metal packing by X-ray tomography. a Reconstructed image from a cross-sectional area of the packing of the immersed BfR. b Reconstructed image of a cross-sectional area of the packing in the aspersed BfR. c Quantification of the fungal biomass attached at different heights inside the metal structured packing of immersed and aspersed BfR production of biomolecules or biocatalytic processes with high added value (Amadio et al. 2013; Gamarra et al. 2010; Lan et al. 2013; Talabardon and Yang 2005). In this work, we designed a fungal BfR on the basis of a metal structured packing generally used in distillation or stripping applications. This packing provides an efficient support for biofilm growth due to its high specific area $\left(800 \mathrm{~m}^{2} / \mathrm{m}^{3}\right)$. Additionally, the support can be considered as an efficient way for bioprocess intensification by promoting the exchanges between the biofilm, gas and liquid phases due to reduced energy consumption. These metal supports can be easily stacked in order to scale-up the process. High-energy X-ray tomography was found to be a useful tool for visualizing and quantifying the fungal biomass in the BfRs. This technique has demonstrated its performance for the characterization of similar processes in previous studies (Aferka et al. 2011; Zune et al. 2013). Indeed, it provides relevant information about the effect of hydrodynamic conditions on biofilm distribution inside the metal structured packing. As was observed in the aspersed mode of BfR, preferential flow paths in the structured packing tend to increase biofilm thickness in localized areas, inducing the appearance of clogs between the corrugated sheets. On the other hand, the immersed mode of BfR promotes homogeneous biofilm distribution with a controlled thickness, allowing it to overcome the diffusional limitation of substrates and metabolites inside the biofilm matrix (Stewart and Franklin 2008). Despite the presence of naturally formed structured channels inside the fungal matrix as reported by Villena et al. (2010), a fraction of the fusion protein secreted remained entrapped in the biofilm. The large size of the fusion protein $(70 \mathrm{kDa})$ could be a factor influencing its recovery in the liquid phase. In the same culture device, productivity of a $7 \mathrm{kDa}$ hydrophobin in a fungal BfR is 2.54 times higher than in a submerged culture in an STR (Khalesi et al. 2014). The immersed BfR works like an improved bubble column, and the absence of agitation allows for the intensification of the process and a reduction of the energy consumption in comparison with an STR. However, oxygen transfer is relatively low in the immersed mode of cultivation, leading to a reduction of the metabolic activity and protein biosynthesis. In context, the aspersed BfR could be seen as a biological gas-liquid contactor in which the high specific area $\left(\mathrm{m}^{2} / \mathrm{m}^{3}\right)$ of the structured packing covered by the biofilm and the liquid film allows for an efficient oxygen mass transfer. Catalytic biofilms implemented in similar devices have already proved their performance for biotransformations requiring efficient gas-liquid exchange (Gross et al. 2007; Li et al. 2013). The efficient oxygen transfer rate and the recirculation of the liquid phase would explain the slightly greater productivity of the fusion protein encountered in the aspersed $\mathrm{BfR}$. In conclusion, the BfR is discharged with several technological constraints. The retention of the microbial biomass inside the support leads to several technical advantages in comparison with submerged cultures (see Table S2 in the supplementary material), such as the possible extension of the 
process to a continuous mode of operation with low energy consumption due to the absence of mechanical stirring (I), the maintenance of a low medium viscosity during the culture (II) and a simplification of the downstream processing operations (III).

Besides these technological advantages, many studies have pointed out that fungal morphology improves metabolite excretion (Grimm et al. 2005). However, this physiological effect is not as clear in our work. Ishida et al. (1998) highlight specific glaB expression in solid-state culture conditions and low expression in submerged culture conditions. However, fusion protein synthesis under the control of the glaB promoter has been identified in each culture condition under several molecular forms. Until now, none of the literature has tackled this subject because all experiments on glaB expression have been performed at a small scale (Hata 2002; Ishida et al. 2000, 2006). In this study, production and quality of the fusion protein are related to the combined effects of fungal physiology and operating culture conditions. Indeed, we observed a significant production of the fusion protein in the $800 \mathrm{rpm} \mathrm{STR}$, suggesting that activation of the glaB promoter is not specific to solid-state fermentation conditions. However, it must be noted that the GlaB protein (with an Ip of 4.68 and a MW of $52.4 \mathrm{kDa}$; source http://web.expasy.org/compute_pi/) has not been identified in any of the 2-D gels because its peptide mass fingerprint has not yet been included in the protein databases. In previous works, Ishida et al. (1998) observed that the expression of $g l a B$ is regulated at the transcriptional level and is induced by starch, low water activity, a high temperature and a physical barrier to hyphal extension, e.g. the specific conditions of solid-state fermentation. However, these experiments were conducted at flask scale and did not take into account a possible protein leakage induced by the mechanical stirring encountered in the stirred bioreactor. The high agitation rate in these systems induces a shear stress. It is well known that an efficient agitation rate improves the oxygen mass transfer rate, but Papagianni and Moo-Young (2002) observed that vacuolation occurring after glucose depletion in submerged cultures makes mycelial hyphae sensitive to shear stress and induces autolysis and hyphal fragmentation. This assumption is supported by the results of Talabardon and Yang (2005) in similar conditions and could explain the sharp biomass drop observed in $800 \mathrm{rpm}$ STR. Consequently, the better secretion level of the proteins in $800 \mathrm{rpm}$ STR can be linked to an increase of cell wall permeability provoked by shear stress as well as the release of fusion protein induced by biomass autolysis. Productivity of the fusion protein reaches intermediary levels in both BfRs. The slightly higher yield obtained in the aspersed BfR could be explained by the greater oxygen availability and the lower water activity of the fungal biofilm, mimicking the environmental conditions in solid-state fermentation and required for efficient pglaB activation (Hisada et al. 2013).
However, an important physiological advantage of the BfR has been observed at the level of the quality of the proteins (recombinant or natural) produced. The alteration of the recombinant protein by native proteases is one of the main constraints for the production of heterologous proteins by filamentous fungi (Yoon et al. 2011). In this work, the glucoamylase region of the fusion protein (Gla::) corresponds to a glucoamylase from $A$. niger (GlaA) without its starchbinding domain. Both native forms of the fusion protein detected in the 2-D gel could be related to G1 and G2 isoforms of GlaA (Lee and Paetzel 2011). The linker region of Gla::GFP contains a cleavage site that could be hydrolyzed by an endopeptidase such as oryzin (AlpA). Oryzin is highly secreted in $800 \mathrm{rpm}$ STR and aspersed BfR. Despite unfavourable $\mathrm{pH}$ conditions for oryzin activity (optimal activity is at $\mathrm{pH} \mathrm{9}$; $\mathrm{http}$ //www.uniprot.org/uniprot/P12547), the fusion protein is largely affected by proteolysis in aspersed BfR and $800 \mathrm{rpm}$ STR. Whereas truncated ::GFP can be found, to a larger extent, in $800 \mathrm{rpm}$ STR and aspersed BfR, the Gla:: fragment has mainly been found in $800 \mathrm{rpm}$ STR conditions only, suggesting that this fragment is absent, degraded or trapped in the fungal biofilm matrix of the BfR. On the basis of these observations, we suggest that the operating conditions and morphological forms of the fungal biomass have an impact on protein secretion efficiency. The enhancement of the quality of the fusion protein produced in the immersed BfR could be linked to posttranslational modification pathways improving folding and stability against protease activity. Among posttranslational modifications, glycosylation allows for the protection of the cleavage sites of the fusion protein from protease activity (Russel et al. 2009). When biomass autolysis occurs in $800 \mathrm{rpm}$ STR, incomplete folding and glycosylation of the fusion protein released in the extracellular medium would increase its sensitivity to endogenous proteases. Thus, the larger amount of ::GFP fragments resulting from the cleavage of the fusion protein leads to the formation of dimers and enhances the fluorescence signal measured in $800 \mathrm{rpm}$ STR (George and Phillips 1997).

In this work, the production of a fusion protein Gla::GFP by the filamentous fungi $A$. oryzae was performed in a bioreactor designed for promoting the formation of biofilm. Despite the use of the specific glaB promoter, different expression and quality levels of the recombinant protein were observed in each condition as well as a modification of the extracellular proteome. The Gla::GFP productivity depends of the combination between a physical effect (including mechanical agitation and diffusional mass transfer) and a physiological effect (including fungal morphology and promoter choice for fusion gene transcription). The best yield was observed in the classical STR but involved biomass leakage and alteration of the recombinant product. On the other hand, production in the immersed BfR enhanced stability of the recombinant 
product despite protease activity. Finally, aspersed and immersed BfRs reached satisfying productivities and are discharged of several technological constraints.

Acknowledgments Quentin Zune is a PhD student funded by Fonds de Recherche pour l'Industrie et l'Agriculture (F.R.I.A.). The authors gratefully acknowledge Samuel Telek and Thierry Salmon for their advice and support during this work.

Conflict of interest The authors confirm no financial support or benefit arising from the research.

\section{References}

Aferka S, Viva A, Brunazzi E, Marchot P, Crine M, Toye D (2011) Tomographic measurement of liquid hold up and effective interfacial area distributions in a column packed with high performance structured packings. Chem Eng Sci 66(14):3413-3422

Amadio J, Casey E, Murphy CD (2013) Filamentous fungal biofilm for production of human drug metabolites. Appl Microbiol Biotechnol 97(13):5955-5963

Barrios-González J (2012) Solid-state fermentation: physiology of solid medium, its molecular basis and applications. Process Biochem 47: $175-185$

Barrios-González J, Baños JG, Covarrubias AA, Garay-Arroyo A (2008) Lovastatin biosynthetic genes of Aspergillus terreus are expressed differentially in solid-state and in liquid submerged fermentation. Appl Microbiol Biotechnol 79(2):179-186

Bauwens J, Millet C, Tarayre C, Brasseur C, Destain J, Vandenbol M, Thonart P, Portetelle D, Pauw ED, Haubruge E, Francis F (2013) Symbiont diversity in Reticulitermes santonensis (Isoptera: Rhinotermitidae): investigation strategy through proteomics. Environ Entomol 42(5):882-887

Bhargav S, Panda BP, Ali M, Javed S (2008) Solid-state fermentation: an overview. Chem Biochem Eng Q 22(1):49-70

Cheng KC, Demirci A, Catchmark JM (2010) Advances in biofilm reactors for production of value-added products. Appl Microbiol Biotechnol 87(2):445-456

El-Enshasy HA (2007) Filamentous fungal cultures - process characteristics, products and applications. In: Yang S-T (ed) Bioprocessing for value-added products from renewable resources. Elsevier, Dayton, pp 225-261

Gamarra NN, Villena GK, Gutiérrez-Correa M (2010) Cellulase production by Aspergillus niger in biofilm, solid-state, and submerged fermentations. Appl Biochem Biotechnol 87:545-551

George N, Phillips J (1997) Structure and dynamics of green fluorescent protein. Curr Opin Struct Biol 7:821-827

Gordon CL, Archer DB, Jeenes DJ, Doonan JH, Wells B, Trinci APJ, Robson GD (2000) A glucoamylase::GFP gene fusion to study protein secretion by individual hyphae of Aspergillus niger. J Microbiol Method 42(1):39-48. doi:10.1016/S0167-7012(00) 00170-6

Grimm LH, Kelly S, Krull R, Hempel DC (2005) Morphology and productivity of filamentous fungi. Appl Microbiol Biotechnol 69(4): 375-384. doi:10.1007/s00253-005-0213-5

Gross R, Hauer B, Otto K, Schmid A (2007) Microbial biofilms: new catalysts for maximizing productivity of long-term biotransformations. Biotechnol Bioeng 98(6):1123-1134

Gutiérrez-Correa M, Ludena Y, Ramage G, Villena GK (2012) Recent advances on filamentous fungal biofilms for industrial uses. Appl Biochem Biotechnol 167(5):1235-1253
Harding MW, Marques LLR, Howard RJ, Olson ME (2009) Can filamentous fungi form biofilms? Trends Microbiol 17(11):475-480. doi:10.1016/j.tim.2009.08.007

Hartingsveldt W, Mattern I, Zeijl CJ, Pouwels P, Hondel CMJJ (1987) Development of a homologous transformation system for Aspergillus niger based on the pyrG gene. Mol Gen Genet 206(1): 71-75. doi:10.1007/BF00326538

Hata Y (2002) Gene expression in solid-state culture of Aspergillus oryzae. Nippon Nog Kag Kaish 76(8):715-718

Hisada H, Sano M, Ishida H, Hata Y, Machida M (2013) Identification of regulatory elements in the glucoamylase-encoding gene ( $\mathrm{glaB}$ ) promoter from Aspergillus oryzae. Appl Microbiol Biotechnol 97(11): 4951-4956

Ishida H, Hata Y, Ichikawa E, Kawato A, Suginami K, Imayasu S (1998) Regulation of the glucoamylase-encoding gene ( $\mathrm{glaB})$, expressed in solid- state culture (koji) of Aspergillus oryzae. J Ferment Bioeng 86(3):301-307

Ishida H, Hata Y, Kawato A, Abe Y, Suginami K, Imayasu S (2000) Identification of functional elements that regulate the glucoamylase-encoding gene ( $\mathrm{glaB}$ ) expressed in solid-state culture of Aspergillus oryzae. Curr Genet 37(6):373-379

Ishida H, Hata Y, Kawato A, Abe Y (2006) Improvement of the glaB promoter expressed in solid-state fermentation (SSF) of Aspergillus oryzae. Biosci Biotechnol Biochem 70(5):1181-1187

Khalesi M, Zune Q, Telek S, Riveros-Galan D, Verachtert H, Toye D, Gebruers K, Derdelinckx G, Delvigne F (2014) Fungal biofilm reactor improves the productivity of hydrophobin HFBII. Biochem Eng J 88:171-178

Lan TQ, Wei D, Yang ST, Liu X (2013) Enhanced cellulase production by Trichoderma viride in a rotating fibrous bed bioreactor. Bioresour Technol 133:175-182

Lee J, Paetzel M (2011) Structure of the catalytic domain of glucoamylase from Aspergillus niger. Acta Crystallogr Sect A: Found Crystallogr F67:188-192

Li XZ, Hauer B, Rosche B (2013) Catalytic biofilms on structured packing for the production of glycolic acid. J Microbiol Biotechnol 23(2):195-204

Papagianni M (2004) Fungal morphology and metabolites production in submerged mycelial process. Biotechnol Adv 22:189-259

Papagianni M, Moo-Young M (2002) Protease secretion in glucoamylase producer Aspergillus niger cultures: fungal morphology and inoculum effects. Process Biochem 37(11):1271-1278. doi:10.1016/ S0032-9592(02)00002-X

Qureshi N, Annous BA, Ezeji TC, Karcher P, Maddox IS (2005) Biofilm reactors for industrial bioconversion process: employing potential of enhanced reaction rates. Microb Cell Fact 4(24):1-21

Rosche B, Li XZ, Hauer B, Schmid A, Buehler K (2009) Microbial biofilms: a concept for industrial catalysis? Trends Biotechnol 27(11):636-643. doi:10.1016/j.tibtech.2009.08.001

Russel D, Oldham N, Davis B (2009) Site-selective chemical protein glycosylation protects from autolysis and proteolytic degradation. Carbohydr Res 344(12):1508-1514

Seferian KR, Tamm NN, Semenov AG, Tolstaya AA, Koshkina EV, Krasnoselsky MI, Postnikov AB, Serebryanaya DV, Apple FS, Murakami MM, Katrukha AG (2008) Immunodetection of glycosylated NT-proBNP circulating in human blood. Clin Chem 54(5): 866-873. doi:10.1373/clinchem.2007.100040

Stewart PS, Franklin MJ (2008) Physiological heterogeneity in biofilms. Nat Rev Microbiol 6(3):199-210. doi:10.1038/nrmicro1838

Sugita A, Sugii A, Sato K, Zhang X-Y, Dai A-L, Taguchi G, Makoto S (2012) Cloning and characterization of gene coding for a major extracellular chitosanase from the koji mold Aspergillus oryzae. Biosci Biotechnol Biochem 76:193-195

Talabardon M, Yang ST (2005) Production of GFP and glucoamylase by recombinant Aspergillus niger: effects of fermentation conditions on 
fungal morphology and protein secretion. Biotechnol Prog 21(5): $1389-1400$

Tamano K, Satoh Y, Ishii T, Terabayashi Y, Ohtaki S, Sano M, Takahashi T, Koyama Y, Mizutani O, Abe K, Machida M (2007) The $\beta-1-3-$ exoglucanase gene $(\operatorname{exg} A)$ of Aspergillus oryzae is required to catabolize extracellular glucan, and is induced in growth on a solid surface. Biosci Biotechnol Biochem 71(4):926-934

Te Biesebeke R, Ruijter G, Rahardjo YSP, Hoogschagen MJ, Heerikhuisen M, Levin A, van Driel KGA, Schutyser MAI, Dijksterhuis J, Zhu Y, Weber FJ, de Vos WM, van den Hondel KAMJJ, Rinzema A, Punt PJ (2002) Aspergillus oryzae in solidstate and submerged fermentations. FEMS Yeast Res 2(2):245-248. doi:10.1111/j.1567-1364.2002.tb00089.x

Te Biesebeke R, Van Biezen N, De Vos WM, Van Den Hondel CAMJJ, Punt PJ (2005a) Different control mechanisms regulate glucoamylase and protease gene transcription in Aspergillus oryzae in solid-state and submerged fermentation. Appl Microbiol Biotechnol 67(1):75-82

Te Biesebeke R, Record E, Van Biezen N, Heerikhuisen M, Franken A, Punt PJ, Van Den Hondel CAMJJ (2005b)
Branching mutants of Aspergillus oryzae with improved amylase and protease production on solid substrates. Appl Microbiol Biotechnol 69(1):44-50

Villena GK, Fujikawa T, Tsuyumu S, Gutiérrez-Correa M (2010) Structural analysis of biofilms and pellets of Aspergillus niger by confocal laser scanning microscopy and cryo scanning electron microscopy. Bioresour Technol 101(6):1920-1926. doi:10.1016/j. biortech.2009.10.036

Ward OP (2012) Production of recombinant proteins by filamentous fungi. Biotechnol Adv 30(5):1119-1139. doi:10.1016/j.biotechadv. 2011.09.012

Yoon J, Maruyama J-I, Kitamoto K (2011) Disruption of ten protease genes in the filamentous fungus Aspergillus oryzae highly improves production of heterologous proteins. Appl Microbiol Biotechnol 89(3):747-759. doi:10.1007/s00253-010-2937-0

Zune Q, Soyeurt D, Toye D, Ongena M, Thonart P, Delvigne F (2013) High-energy X-ray tomography analysis of a metal packing biofilm reactor for the production of lipopeptides by Bacillus subtilis. J Chem Technol Biotechnol 89(3):382390. doi: $10.1002 /$ jetb. 4128 